\title{
Gamma 3 U-Blade lag screws in patients with trochanteric femur fractures: are rotation control lag screws better than others?
}

\author{
Jehyun Yoo' ${ }^{1}$ Sangmin $\mathrm{Kim}^{2}$, Junyoung $\mathrm{Choi}^{3}$ and Jihyo Hwang ${ }^{3^{*}}$ (D)
}

\begin{abstract}
Background: Intramedullary hip nails may be classified as blades or screws depending on the type of lag screw used. Recently, a combination of lag screw types with a U-clip insertion has also been used. The purpose of this study was to evaluate the clinical and radiological outcomes of these new screw types.

Methods: A total of 185 patients with trochanteric femoral fractures (age $\geq 65$ years) who underwent surgery with intramedullary nails were selected. Surgeries with InterTrochanteric/SubTrochanteric (ITST), Proximal Femoral Nail Antirotation (PFNA), and Gamma 3 U-Blade lag screws were performed between January 2011 and June 2016. The AO/OTA classification, presence of a basicervical fracture type on 3D-CT, BMI, BMD, reduction quality, position of the lag screw, TAD (tip apex distance) of the lag screw, sliding distance of the lag screw, varus change (neck shaft angle), radiological union period, fixation failure and functional outcome as determined by walking ability were analyzed.

Results: There were $3 / 60$ (5.0\%) cases of fixation failure in the ITST group, all caused by cut-out; $4 / 57$ (7.0\%) in the PFNA II group: 3 caused by cut-through and 1 by metal fracture; 1/68 (1.5\%) in the Gamma 3 U-Blade lag screw group $(P=0.301)$. In each group, the sliding distance of the lag screw showed a significant difference $(P=0.017)$, whereas significant sliding over $10 \mathrm{~mm}$ showed no statistically significant results.

Conclusion: There was only one (1.5\%) case of fixation failure in the Gamma 3 U-Blade lag screw group. The sliding distance of the U-Blade was found to be in the middle, between the PFNA II (shorter) and ITST (longer) implants. The new rotational control lag screw seems to be comparable to other screw types.
\end{abstract}

Keywords: ITST, PFNA II, Gamma 3, Trochanteric fracture

\section{Background}

Hip fractures are the third most common type of fractures after distal radius fractures and hand fractures. Hip fractures are the most common type of fracture among elderly people. In particular, the prevalence of trochanteric fractures compared with femoral neck fractures has gradually increased. The average age of patients with these types of fractures is

\footnotetext{
* Correspondence: hwangjihyo7309@gmail.com

${ }^{3}$ Department of Orthopaedic Surgery, Gangnam Sacred Heart Hospital, Hallym University College of Medicine, 1 Singil-ro, Yeongdeungpo-gu, Seoul 07441, Republic of Korea

Full list of author information is available at the end of the article
}

also gradually increasing. Unlike other fractures, trochanteric fractures can be fatal and, thus, they deserve special care and attention from orthopedic surgeons [1]. Using intramedullary nails during osteosynthesis has also been reported to be biomechanically superior to the use of compression hip screws [2]. InterTrochanteric/SubTrochanteric (ITST, Zimmer Biomet, Warsaw, IN, US) and Proximal Femoral Nail Antirotation (PFNA, Synthes, Paoli, Switzerland) screws are commonly used options for intramedullary nailing, and they might be representative of the blade type and screw type of lag screws. The Gamma nail has been improved and used in Asian patients who

(C) The Author(s). 2019 Open Access This article is distributed under the terms of the Creative Commons Attribution 4.0 International License (http://creativecommons.org/licenses/by/4.0/), which permits unrestricted use, distribution, and 
have smaller body sizes $(170 \mathrm{~mm})$ as a fourthgeneration Gamma nail (Asia-Pacific and Japanese versions). After that, the Gamma 3 nail model designed with the use of a U-Blade lag screw was developed to provide improved outcomes when treating patients with unstable proximal femur fractures, and for those at high risk of rotation, this model is the newest model in the Gamma series. So far, there have been limited results for this newest type of Gamma nail $[3,4]$.

In this study, we sought to compare radiological and functional outcomes, including implant-related complications, among three different types of screws: the most recently developed rotation control (RC) Gamma 3 screw (Stryker Trauma GmbH, Schoenkirchen, Germany) (Fig. 1), the latest PFNA II blade lag screw (Fig. 2) and a traditional InterTrochanteric/SubTrochanteric (ITST) lag screw (Fig. 3).

\section{Methods}

\section{Study design}

This study was approved by the local Institutional Review Board. We obtained consent from all patients with permission to operate. All the data were analyzed by retrospectively reviewing the medical charts, $\mathrm{X}$-rays and phone interviews in terms of the functional outcomes.

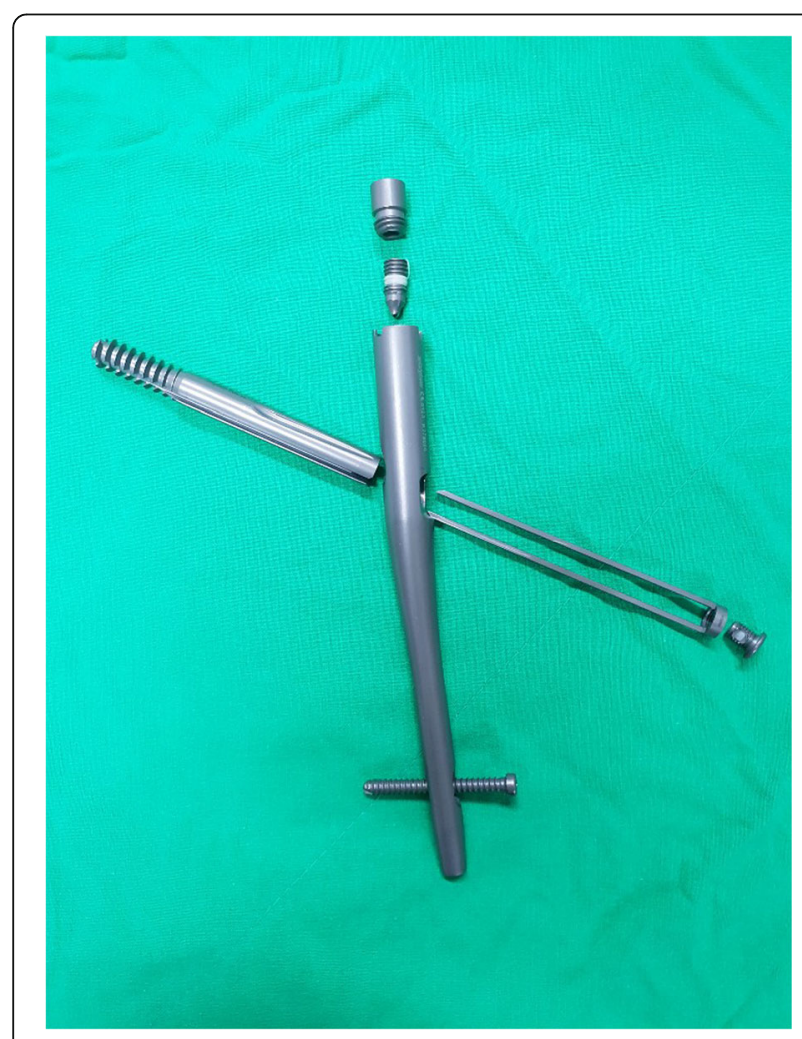

Fig. 1 Photograph of rotation control (RC) of the Gamma 3 screw (Stryker, Schonkirchen, Germany)

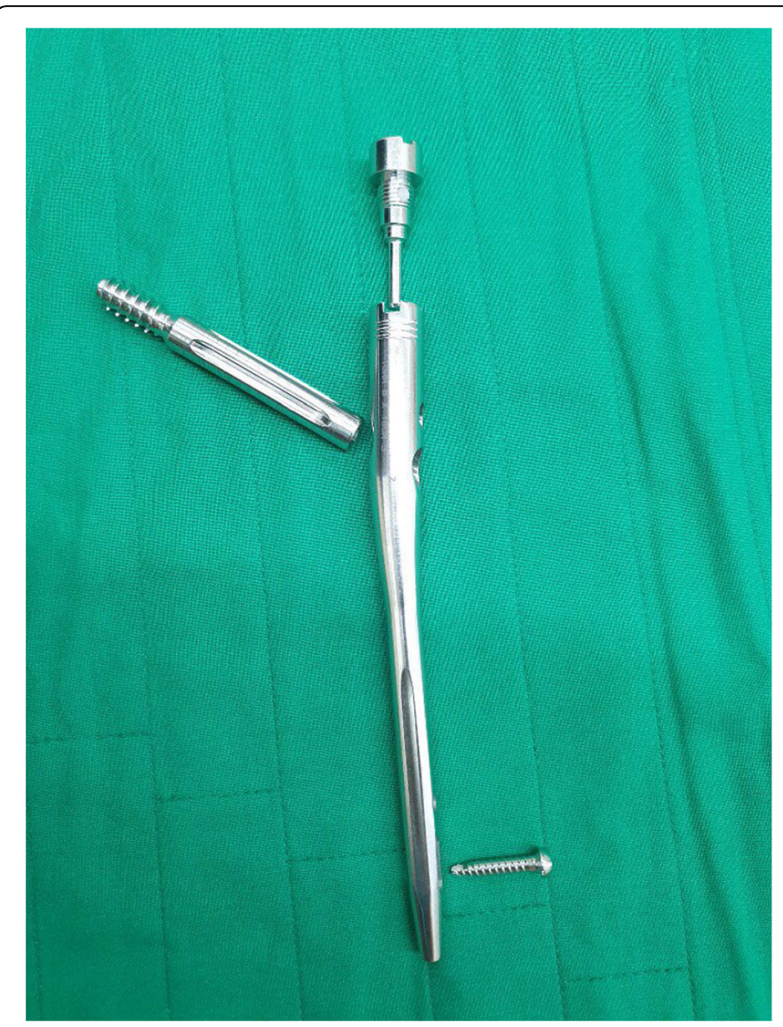

Fig. 2 Photograph of PFNA (Proximal Femoral Nail Antirotation, Synthes, Paoli, Switzerland)

\section{Inclusion and exclusion criteria}

We included patients with at least 12 months of followup between January 2011 and June 2016 who could walk on their own. Patients aged 65 years or older were selected. Basicervical types of trochanteric fractures were included. The exclusion criteria were as follows: patients who could not walk on their own prior to the injury, patients who had other pathological fractures due to causes other than osteoporosis, patients who died during the follow-up, patients with high-energy injuries such as motor vehicle accidents or falling from a height, and patients who had less than 12 months of follow-up. The average follow-up periods for patients with ITST, PFNA II, and Gamma 3 RC nails were 28.5 (12-53), 37 (12$143)$, and 14.8 (12-28) months, respectively. The types of implants were randomly chosen, and the use of the Gamma 3 U-Blade lag screw started in 2014, as it was introduced in this period.

\section{Fracture classification}

Fractures were classified by two physicians according to the AO/OTA classification [5]. All fractures were also analyzed using preoperative $\mathrm{CT}$ imaging to determine the configuration of fracture patterns, the presence of greater trochanter comminution and whether the fracture was of a basicervical fracture type. This fracture 


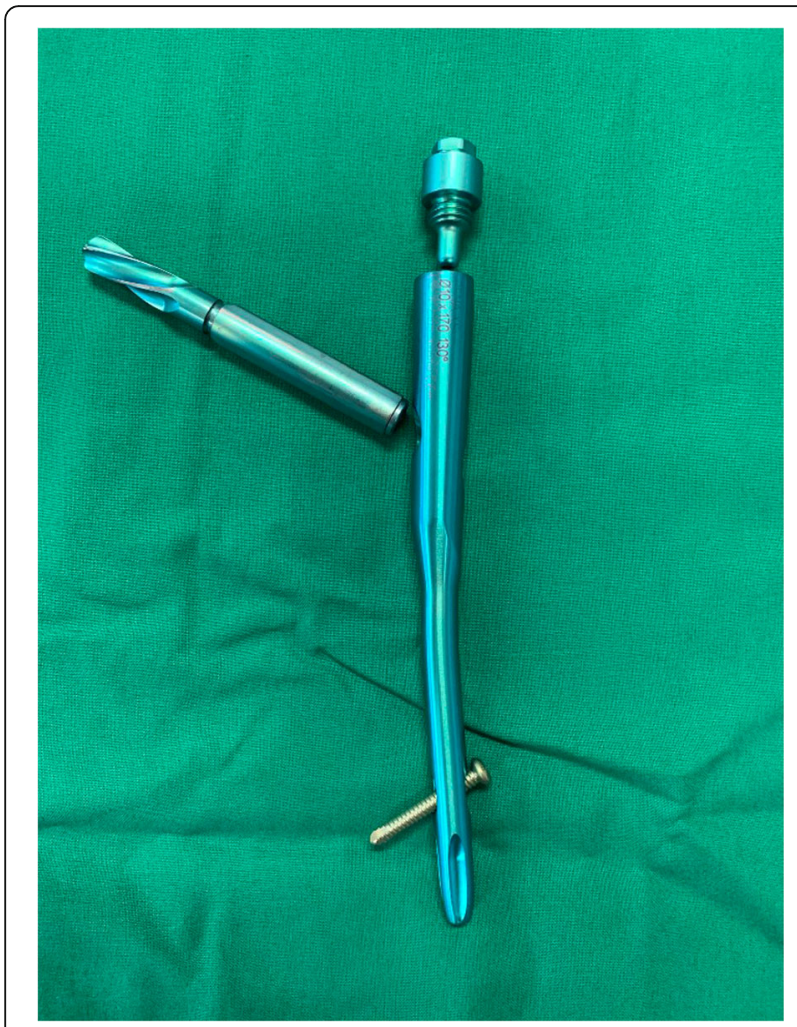

Fig. 3 Photograph of InterTrochanteric/SubTrochanteric (ITST), Zimmer Biomet, Warsaw, IN, US)

type was defined as a partial capsular fracture, which can be a variant of a trochanteric fracture. This fracture type corresponds to the A1 fracture type on the AO/OTA classification.

\section{Analyzed variables}

Altogether, there were 60 cases of ITST nails, 68 of Gamma 3 RC nails, and 57 of PFNA II nails. We also compared the body mass index (BMI), bone mineral density (BMD), degree of fracture reduction, position of the lag screw in the femoral head, tip apex distance (TAD), sliding distance of the lag screw, changes in the neck shaft angle, radiological bone union period, and fixation failure and its causes. For the functional outcomes, the ability status was evaluated by Koval grade [6, 7] (Table 1). Recovery

Table 1 Categories of ambulatory ability

\footnotetext{
1. Independent community ambulator

2. Community ambulatory with cane

3. Community ambulatory with walker/crutches

4. Independent household ambulator

5. Household ambulatory with cane

6. Household ambulatory with walker or crutches

7. Nonfunctional ambulator ${ }^{\mathrm{a}}$
}

${ }^{a}$ Used only for after-fracture ambulation rates were calculated as the proportion of the patients who obtained the preinjury ambulatory status.

\section{Surgical procedure}

The subjects were asked to assume a supine position on the fracture bed and received general or spinal anesthesia. After fixation in the fracture bed, manual reduction was performed through traction and internal rotation and/or adduction. Satisfactory results were confirmed via fluoroscopy. When the manual reduction was unsatisfactory, a long Kelly, Hohmann retractor or bone hook was used to compress the lateral or anterior cortex and to pull the medial cortex for reduction. No invasive open reduction was performed. We attempted manual reduction to maintain the continuity of the medial and anterior cortices. After manual reduction, an entry point was designated, a guide pin was inserted, and proximal reaming was performed in the proximal area using a conical reamer that was thicker than the nail. When a fracture gap remained, we reduced it using a compression technique for each implant. The distal fixation screw was fixed in a static locking mode regardless of the fracture type in all the patients based on the surgeon's preference. Approximately $2-3$ days postoperatively, when the patients could tolerate weight-bearing in a sitting position, the patients were asked to try to stand using a tilt table. Walking was allowed when the pain became tolerable. Restricted weight-bearing was taught and initiated by touching approximately $20 \mathrm{~kg}$ on a scale; the patients were allowed to walk using the parallel bar or rolling walker. Various weight-bearing training exercises were performed not based on the reduction or bone quality but only based on the subject's pain level and medical condition. All rehabilitation programs were conducted equally in all patients. All the patients were discharged or transferred with proper walking aids, such as wheelchairs or walkers.

\section{Outcome parameters}

Cut-out was defined as penetration through the femoral head that was visible on X-ray, while cut-through was defined as the perforation of the femoral head from centric movement and without lateral movement by the lag screw. The lag screw position in the femoral head was measured from the anteroposterior (AP) and lateral images. The general rule was to measure the position from the final follow-up X-ray images. Centric position was defined as a screw positioned in the center of both the $\mathrm{AP}$ and lateral images, while eccentric position was defined as the screw deviating from the center on any of the views. Reduction quality was also evaluated based on radiological evidence. Maintaining continuity of the medial cortex on AP view, the anterior cortex in the lateral view was defined as anatomical reduction. 
Successful reduction in both views was defined as anatomical reduction, whereas continuity not maintained in any of the views was defined as non-anatomical reduction. The sliding distance and neck shaft angle, which can represent the shortening of and varus change in the fracture site, were calculated as differences between the initial X-ray and final X-ray. All the parameters obtained in the X-ray were adjusted by the calibration of the magnification of the real size and angle of the inserted implants. Significant sliding of the lag screw was defined arbitrarily by the authors, as an irritation sign due to the prominent lateral impingement without deep or superficial infection, as a lag screw sliding distance $\geq 10 \mathrm{~mm}$ in the plain X-ray or the removal of the lag screw due to one or both reasons. The excessive angular change was also arbitrarily defined as $10^{\circ}$ or more. For the union, a clinical union was determined when the pain scale improved during the follow-up period and with the absence of pain or tenderness during weight-bearing. Radiological union was defined when the fracture line was lost and when three or more external or internal calluses were formed in the anteroposterior and lateral radiological images taken during the follow-up period [8]. For the analysis of fracture types and radiologic union, three orthopedic surgeons performed the measurements with an interval to minimize interobserver error.

\section{Complications}

For implant-related complications, screw cut-out, cutthrough and back-out, as well as nail or screw breakage, were analyzed. Other medical complications (e.g., infection, pressure ulcers, pneumonia, urinary tract infections, delirium, cardiovascular complications, and deep vein thrombosis) were also investigated but not statistically analyzed.

\section{Statistical analysis}

All continuous variables were analyzed for normality by the one-sample Kolmogorov-Smirnov test. For the continuous variables with normal distribution, such as BMI and the varus change in the neck shaft angle, $t$ test was performed. For continuous variables without a normal distribution, such as age, sliding distance and TAD, the Kruskal-Wallis test was performed. The other categorical variables, such as sex, classification, reduction quality, and complications, were analyzed by Pearson's Chi-square test. Statistical analysis was performed using IBM SPSS (Version 25, Chicago, IL). Statistical significance was defined as a $P$ value less than 0.05 .

\section{Results}

ITST $(n=60)$

The mean age was $78.5 \pm 7.0$ years, with a female-tomale ratio of 44 to 16 . The BMI was $22.8 \pm 3.9$, and the
$T$ score of BMD was $-2.6 \pm 1.3$. A total of 38 cases were classified as 31A1 based on AO/OTA on the preoperative X-ray, 6 were basicervical fracture types on 3-D CT imaging, and 37 were comminuted in the greater trochanter. Fifty-seven (95\%) patients gained union. Union was gained at an average of 18.7 weeks (12-40 weeks). The TAD was $19.9 \pm 0.98 \mathrm{~mm}$. The sliding distance was $5.6 \pm 3.6 \mathrm{~mm}$, and three cases migrated over $10 \mathrm{~mm}$. The change in the neck shaft angle was $2.3^{\circ} \pm 6.08$; four cases were over $10^{\circ}$. The position of the lag screw was centric in 45 cases, and 43 cases were anatomically reduced. Three cases demonstrated a cut-out lag screw. One case is shown in Fig. 4. The mean Koval grade at the final visit was $2.9(1-7)$. The overall recovery rate of ambulatory status was $46.5 \%$.

PFNA II $(n=57)$

The mean age was $79.5 \pm 7.0$ years, with a female-tomale ratio of 42 to 16 . The BMI was $21.4 \pm 1.4$, and the $T$ score of BMD was $-2.8 \pm 1.4$. A total of 24 cases were type $31 \mathrm{~A} 1$, and 31 cases were classified as $\mathrm{A} 2$ on $\mathrm{AO} /$ OTA on the preoperative X-ray. Five cases were basicervical fracture types on 3-D CT imaging, and 37 cases were comminuted in the greater trochanter. Fifty-three patients $(92.8 \%)$ out of 57 gained complete union. The average union was gained at 17.6 weeks (12-24 weeks). The TAD was $19.2 \pm 5.02 \mathrm{~mm}$. The sliding distance was $3.3 \pm 3.6 \mathrm{~mm}$, and there was no excessive migration. The change in the neck shaft angle was $1.3^{\circ} \pm 1.20$. Two patients showed excessive varus change over $10^{\circ}$. The position of the lag screw was centric in 43 cases, and 40 cases were anatomically reduced. Four cases had nail complications: three were cut-through, and one was nail breakage. The cut-through case is shown in Fig. 5. The mean Koval grade at the final visit was 3.1. The overall recovery rate of ambulatory status compared to the preoperative status was $46.8 \%$.

\section{Gamma 3 U-Blade $(n=68)$}

The mean age was $79.2 \pm 7.5$ years, with a female-tomale ratio of 51 to 17 . The BMI was $22.2 \pm 3.9$, and the $T$ score of BMD was $-2.7 \pm 1.2$. A total of 21 cases were $31 \mathrm{~A} 1$ type, 41 cases were $\mathrm{A} 2$, and 6 cases were $\mathrm{A} 3$ on $\mathrm{AO} / \mathrm{OTA}$ on the preoperative X-ray. A total of 9 cases were basicervical fracture types on 3-D CT imaging, and another 39 cases were comminuted in the greater trochanter. One case of delayed union and one of nonunion due to screw cut-out are shown. One patient with delayed union obtained complete union without the need for any additional procedure at 36 weeks after the operation. The union rate was $98.5 \%$, with an average of 19.9 weeks (12-36 weeks). The TAD was $18.1 \pm 4.45 \mathrm{~mm}$. The sliding distance was $3.8 \pm 3.1 \mathrm{~mm}$, and there were three cases of excessive migration. The change in the 


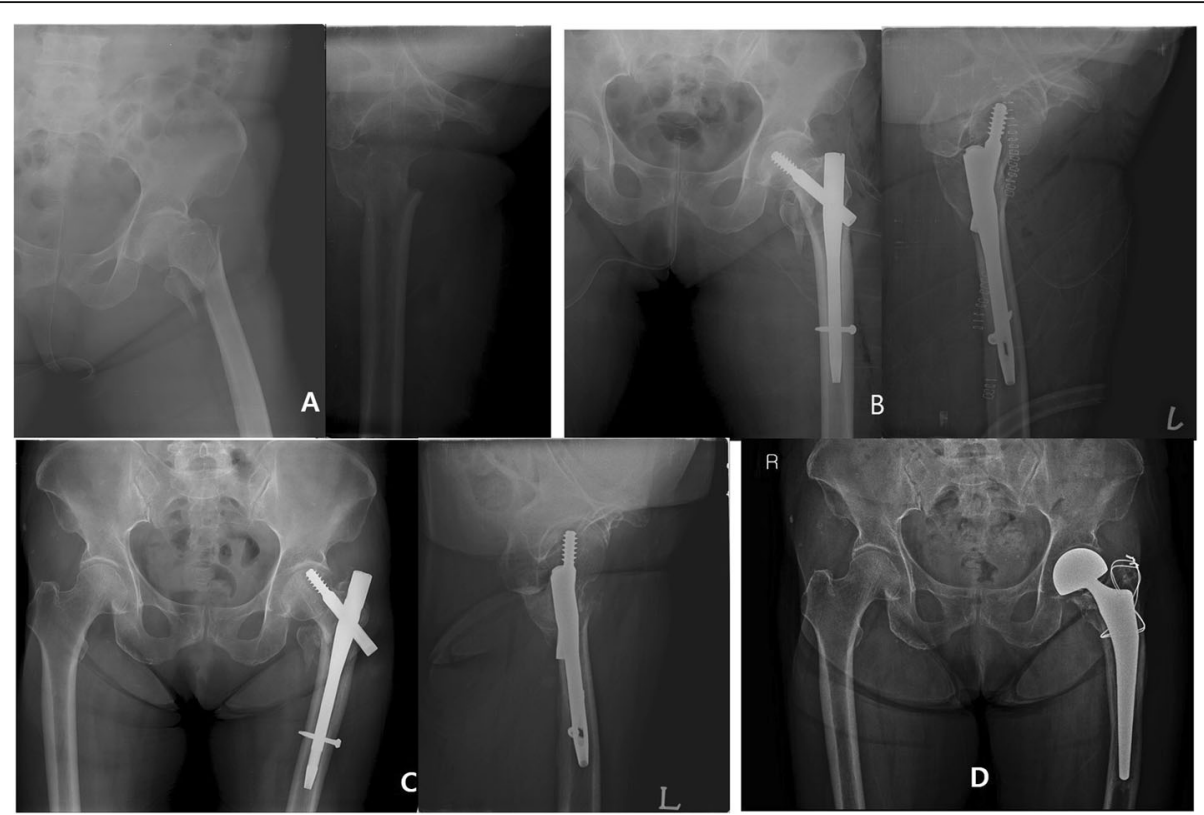

Fig. 4 A 70-year-old woman with an A22 fracture and a large posteromedial fragment on the day of the trauma (a). She underwent ITST surgery (b). The lag screw demonstrated cut-out 3 months postoperatively (c). Bipolar hemiarthroplasty was performed (d)

neck shaft angle was $2.2^{\circ} \pm 5.46$. A total of $3 / 68$ cases showed a change of $10^{\circ}$ or more. The position of the lag screw was centric in 53 cases, and 53 cases were anatomically reduced. One case is shown as a cut-out of the femoral head (Fig. 6). The mean Koval grade at the final visit was $2.7(1-7)$. The overall recovery rate of ambulatory status was $49.8 \%$. The statistically compared data are presented in Table 2.

\section{Discussion}

Rotation of the proximal fragment or lag screw is related to the initiation of screw migration and consequent fixation failure [9], so many efforts for lag screw design, especially the prevention of rotation, have evolved. Proximal Femoral Nail Antirotation (PFNA) and Gamma 3 U-Blade screws represent some of the most evolved models for the control of the early motion of lag screws,

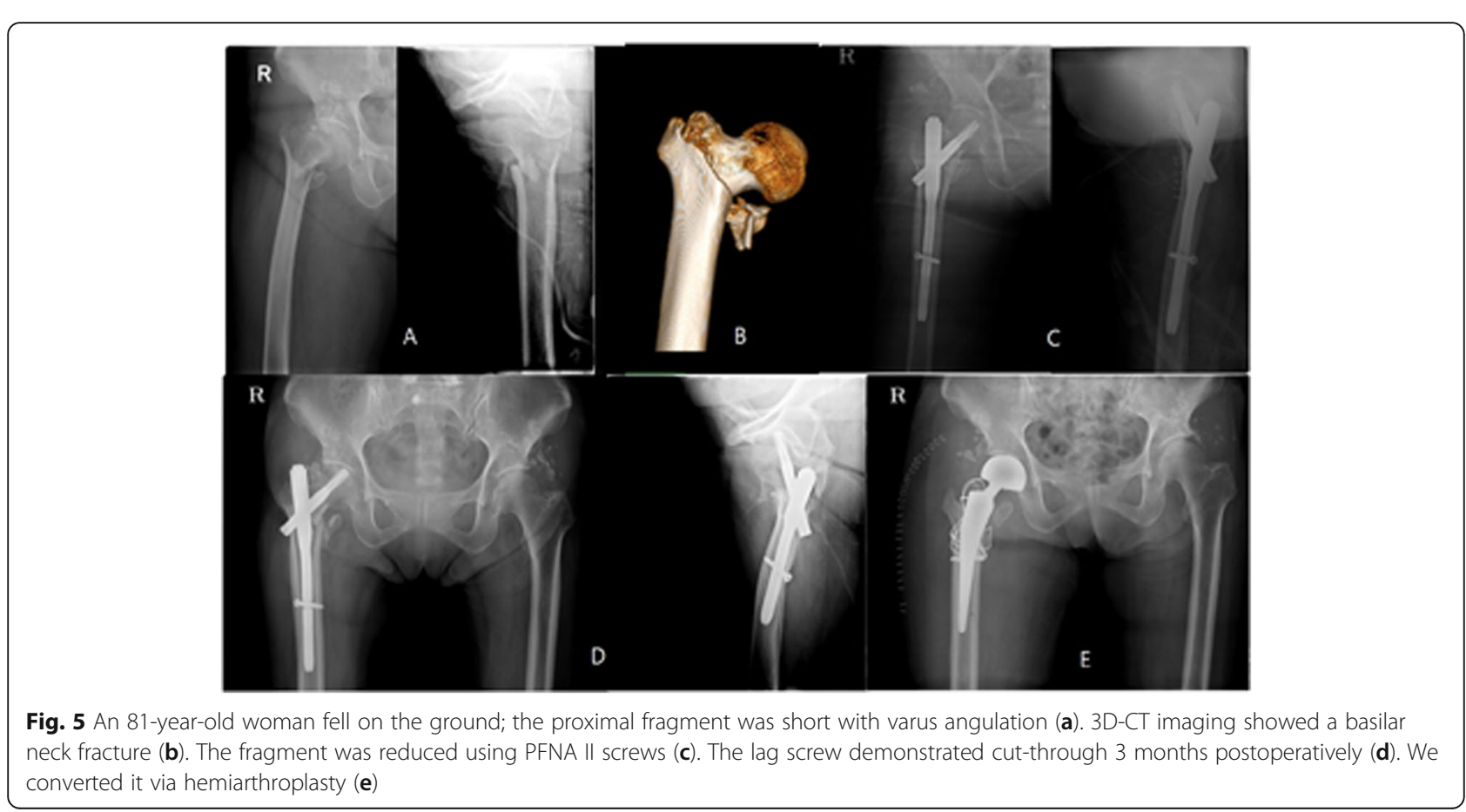



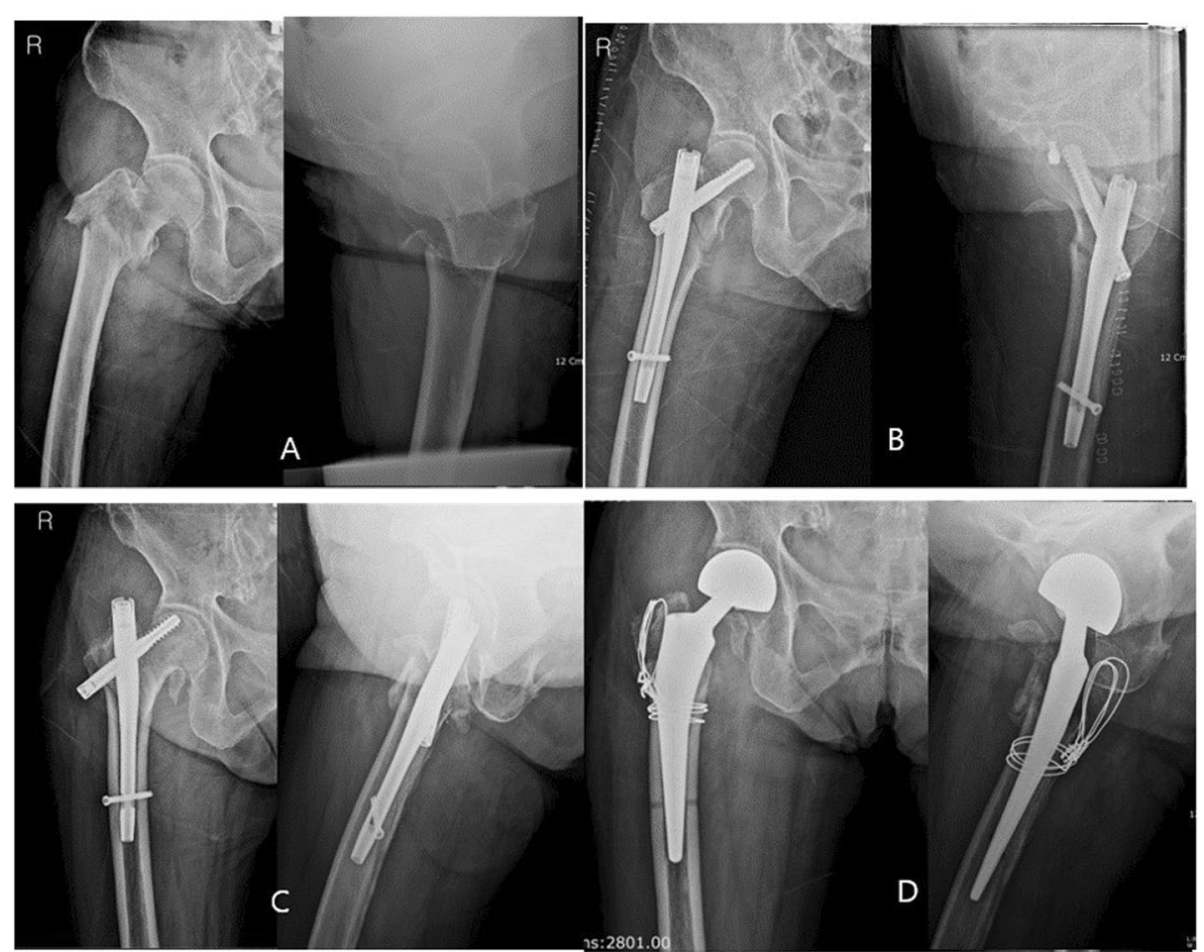

Fig. 6 An 83-year-old woman suffered from a fall from a height at home; the fracture type was reverse oblique (A32) (a). The fragment was reduced using a Gamma 3 RC screw $(\mathbf{b})$. The lag screw demonstrated cut-out of the head 3 months postoperatively (c). We converted it via hemiarthroplasty $(\mathbf{d})$

such as toggling, rotation, and migration. Although our study did not reveal differences in clinical results, lag screw migration in terms of the sliding distance showed a significant difference, and these rotation control lag screws can be superiorly resistant to lag screw migration. Although only a slight difference was shown in our study, it suggests that the rotation control lag screw might be more effective than other types of screws.

We were unable to find any statistically significant differences among the three different types of nail systems. ITST nails had a greater sliding distance than the other two nailing systems. However, sliding distance alone does not affect surgical outcomes or prognosis. It should be noted that metal irritation due to sliding distance or metal removal may result in an excessive sliding distance. Sliding distance can also represent the migration of lag screws, and it can be a potential risk factor for lag screw-related complications. The newly designed Gamma 3 RC lag screw is thought to have few implantrelated complications. We found that cut-through was the most common complication among the blade types, while cut-out was most common among the screw types. As is the case with numerous previous studies, it is difficult to predict treatment outcomes based on screw design, but the latest implants may prevent further complications. In terms of the factors of fixation failure for surgeons, the implant choice can affect the clinical outcomes when the fracture configurations look unstable. Gamma 3 U-Blade screws can be a good option for trochanteric hip fractures in the clinical field.

The CT scan is a popular and beneficial tool for the preop or postop evaluation of hip fractures. In the current study, a CT scan was routinely performed for more information about the fracture configurations. CT scans are also good tools for the evaluation of coronal fracture patterns [10]. A new classification for CT scans has been proposed, indicating the significance of CT scans for hip fractures $[11,12]$. The extension of fracture lines to the greater trochanter area and fracture levels, such as with basicervical fracture types, might affect the reduction quality of intramedullary nailing, so we also analyzed these factors. The comminution of the greater trochanter did not have any significance, but the fracture level for basicervical type fractures was related to fixation failure in this study. A basicervical type fracture can be considered an unstable fracture in intramedullary nailing. In other words, it can be thought of as stable from the perspective of femoral neck fractures but unstable from the perspective of trochanteric fractures. A good example would be a fracture with a pistol grip deformity that shows significant varus angulation. In our study, $30.3 \%(56 / 185)$ of cases showed this type of 
Table 2 Comparative statistical analysis of three groups

\begin{tabular}{|c|c|c|c|c|}
\hline & ITST $(n=60)$ & PFNA $(N=57)$ & U-Blade $(n=68)$ & $P$ value \\
\hline Age (years) & $78.5 \pm 7.0$ & $79.5 \pm 7.0$ & $79.2 \pm 7.5$ & 0.187 \\
\hline Gender (female:male) & $44: 16$ & $42: 15$ & $51: 17$ & 0.977 \\
\hline \multicolumn{5}{|l|}{ AO classification } \\
\hline $31 \mathrm{~A} 1$ & 38 & 24 & 21 & \multirow[t]{3}{*}{1.000} \\
\hline $31 \mathrm{~A} 2$ & 22 & 31 & 41 & \\
\hline $31 \mathrm{~A} 3$ & 0 & 2 & 6 & \\
\hline $\mathrm{BMI}\left(\mathrm{kg} / \mathrm{m}^{2}\right)$ & $22.8 \pm 3.9$ & $21.4 \pm 3.9$ & $22.2 \pm 3.9$ & 0.162 \\
\hline BMD (T score) & $-2.6 \pm 1.3$ & $-2.8 \pm 1.4$ & $-2.7 \pm 1.2$ & 1.000 \\
\hline Basicervical fracture type on 3D-CT & $6(10 \%)$ & $5(8.7 \%)$ & $9(13.2 \%)$ & 0.145 \\
\hline GT comminution on 3D-CT & $37(61.7 \%)$ & $37(64.9 \%)$ & $39(57.4 \%)$ & 0.684 \\
\hline TAD of lag screw (mm) & $19.9 \pm 0.98$ & $19.2 \pm 5.02$ & $18.1 \pm 4.45$ & 0.835 \\
\hline Sliding distance of lag screw (mm) & $5.6 \pm 3.6$ & $3.3 \pm 3.6$ & $3.8 \pm 3.1$ & 0.017 \\
\hline Excessive sliding over $10 \mathrm{~mm}$ & 3 & 0 & 3 & 0.247 \\
\hline Varus change $\left(^{\circ}\right)$ & $2.3^{\circ} \pm 6.08$ & $1.3^{\circ} \pm 1.20$ & $2.2^{\circ} \pm 5.46$ & 0.762 \\
\hline Excessive change over $10^{\circ}$ & 4 & 2 & 3 & 0.634 \\
\hline \multicolumn{5}{|l|}{ Position of lag screw } \\
\hline Centric & 45 & 43 & 53 & \multirow[t]{2}{*}{0.914} \\
\hline Eccentric & 15 & 14 & 15 & \\
\hline \multicolumn{5}{|l|}{ Reduction quality } \\
\hline Anatomical & 43 & 43 & 53 & \multirow[t]{2}{*}{0.572} \\
\hline Non-anatomical & 17 & 14 & 15 & \\
\hline Fixation failure & $3(5.0 \%)$ & $4(7.0 \%)$ & $1(1.5 \%)$ & 0.301 \\
\hline \multicolumn{5}{|l|}{ Cause of failure } \\
\hline Cut-out & 3 & 0 & 1 & \multirow[t]{3}{*}{0.092} \\
\hline Cut-through & 0 & 3 & 0 & \\
\hline Nail breakage & 0 & 1 & 0 & \\
\hline Walking ability recovery (Koval grade) & $52.7 \%$ & $46.8 \%$ & $49.8 \%$ & 0.732 \\
\hline
\end{tabular}

fracture on CT scans. Among patients in the fixation failure groups, $62.5 \%(5 / 8)$ showed this type of fracture.

There are still controversies surrounding studies comparing intramedullary nail systems. There is a wide variety of studies comparing blades versus screws and the use of one screw versus two screws [13-20]. Researchers have been unable to find any biomechanical or clinical differences between the different screw designs (screw type versus blade type). Unlike previous studies, we included Gamma $3 \mathrm{RC}$ lag screws, the latest model among one-screw types, and PFNA II, the latest model among blade types, as well as ITST, which was the popular conventional screw design, to determine the advantages and disadvantages among these three different types of implants. Since the latest Gamma $3 \mathrm{RC}$ lag screw type model has not been compared often, including it in the comparison was even more meaningful. According to Lang et al. [3], when conventional nails and the newly designed RC screw were compared in cases of unstable trochanter fractures, cut-out complications did not decrease with either design. We could not show that Gamma 3 RC lag screws were superior. Only a few studies have compared three or more nailing systems. Ma et al. [21] reported that InterTan, a two-screw type, was superior to PFNA II and Gamma 3 nails, which are onescrew types. Several papers comparing two-nail systems have already been published [22, 23], and the clinical outcomes from each of these nails have been reported [23-25]. However, to our knowledge, this is the first study to compare three one-screw types.

We acknowledge that there are major limitations in this study. First, there were a limited number of patients and a difficult follow-up because the patients were geriatric. If patients died or could not be followed properly, treatment outcomes could not be fully evaluated. Therefore, the results might not be sufficiently suitable for statistical analysis. Second, because the Gamma 3 RC lag screw is the latest model, this group had a shorter 
follow-up period than the other groups. However, implant-related complications are usually determined within 3 months; thus, shorter overall periods of followup might not be affected in the current study. Last, the data from X-rays, especially the neck-shaft angle and sliding distance, can deviate due to the observers or Xray evaluations.

\section{Conclusions}

PFNA II, Gamma 3 U-Blade and ITST nails can be a good option for the treatment of trochanteric fractures. The sliding distance, which can be an indicator of lag screw migration and cut-out, was superior in the groups with rotation control lag screws (PFNA II and Gamma 3 U-Blade) than in the ITST group. Altogether, the results show that the new rotation control lag screw is not superior to the other types of screws. The numerical complication rate was lower, and the sliding distance, which might be related to implant-related complications, was shorter for the rotation control lag screws than for the conventional lag screws (ITST). Additional studies are necessary to determine whether better clinical results are achieved with lower fixation failure rates or whether improved function is achieved with rotation control lag screws such as Gamma 3 for trochanteric femur fractures.

\section{Abbreviations}

ITST: InterTrochanteric/SubTrochanteric; PFNA: Proximal Femoral Nail Antirotation; RC: rotation control

\section{Acknowledgements}

Not applicable.

\section{Authors' contributions}

JY assembled the study design and performed the data collection and analysis. SK collected the clinical follow-up data. JC performed the data analysis. JH wrote the manuscript. All authors read and approved the final manuscript.

\section{Funding}

There is no financial or personal relationship with other people or organizations that could inappropriately influence (bias) our work. There is no employment, consultancies, stock ownership, honoraria, paid expert testimony, patient applications/registrations, and grants or other funding. Availability of data and materials

All data in this article are available.

\section{Ethics approval and consent to participate}

This study was approved by the local Institutional Review Board (HUGSHH IRB, IRB No. 2017-07-61(201)). All investigations were conducted in conformity with the ethical principles of research. Written informed consent for this study was obtained from all patients.

\section{Consent for publication}

All authors gave their consent for publishing.

\section{Competing interests}

The authors declare that they have no competing interests.

\section{Author details}

${ }^{1}$ Department of Orthopaedic Surgery, Hallym University Sacred Heart Hospital, Hallym University School of Medicine, Anyang, Republic of Korea.
2Department of Orthopaedic Surgery, Korea University Guro Hospital, Seoul, Republic of Korea. ${ }^{3}$ Department of Orthopaedic Surgery, Gangnam Sacred Heart Hospital, Hallym University College of Medicine, 1 Singil-ro, Yeongdeungpo-gu, Seoul 07441, Republic of Korea.

Received: 29 March 2019 Accepted: 22 October 2019

Published online: 16 December 2019

\section{References}

1. Domingo LJ, Cecilia D, Herrera A, Resines C. Trochanteric fractures treated with a proximal femoral nail. Int Orthop. 2001;25(5):298-301.

2. Huang SG, Chen B, Zhang Y, Nie FF, Ju L, Li M, Zhang YH. Comparison of the clinical effectiveness of PFNA, PFLCP, and DHS in treatment of unstable intertrochanteric femoral fracture. Am J Ther. 2017;24(6):e659-66.

3. Lang NW, Arthold C, Joestl J, Gormasz A, Boesmueller S, Hajdu S, Sarahrudi K. Does an additional antirotation U-Blade (RC) lag screw improve treatment of AO/OTA 31 A1-3 fractures with gamma 3 nail? Injury. 2016;47(12):2733-8.

4. Choi K, Kim Y, Zhou S, Hwang J. Failure of a rotation control Gamma 3 lag screw used to treat a trochanteric fracture. Hip Pelvis. 2018;30(2):129-33.

5. Fung $W$, Jonsson A, Buhren V, Bhandari M. Classifying intertrochanteric fractures of the proximal femur: does experience matter? Med Princ Pract. 2007;16(3):198-202.

6. Koval KJ, Skovron ML, Aharonoff GB, Meadows SE, Zuckerman JD. Ambulatory ability after hip fracture. A prospective study in geriatric patients. Clin Orthop Relat Res. 1995;310:150-9.

7. Koval KJ, Aharonoff GB, Rosenberg AD, Bernstein RL, Zuckerman JD. Functional outcome after hip fracture. Effect of general versus regional anesthesia. Clin Orthop Relat Res. 1998;348:37-41.

8. Corrales LA, Morshed S, Bhandari M, Miclau TIII. Variability in the assessment of fracture-healing in orthopaedic trauma studies. J Bone Joint Surg Am. 2008;90(9):1862.

9. Kim TY, Lee YB, Chang JD, Lee SS, Yoo JH, Chung KJ, Hwang JH. Torsional malalignment, how much significant in the trochanteric fractures? Injury. 2015;46(11):2196-200.

10. Cho JW, Kent WT, Yoon YC, Kim Y, Kim H, Jha A, Durai SK, Oh JK. Fracture morphology of AO/OTA 31-A trochanteric fractures: a 3D CT study with an emphasis on coronal fragments. Injury. 2017;48(2):277-84.

11. Shoda E, Kitada S, Sasaki Y, Hirase H, Niikura T, Lee SY, Sakurai A, Oe K, Sasaki T. Proposal of new classification of femoral trochanteric fracture by three-dimensional computed tomography and relationship to usual plain Xray classification. J Orthop Surg. 2017;25(1):2309499017692700.

12. Cho YC, Lee PY, Lee CH, Chen CH, Lin YM. Three-dimensional CT improves the reproducibility of stability evaluation for intertrochanteric fractures. Orthop Surg. 2018;10(3):212-7.

13. Huang $X$, Leung F, Liu M, Chen L, Xu Z, Xiang Z. Is helical blade superior to screw design in terms of cut-out rate for elderly trochanteric fractures? A meta-analysis of randomized controlled trials. Eur J Orthop Surg Traumatol. 2014;24(8):1461-8.

14. Leung F, Gudushauri P, Yuen G, Lau TW, Fang C, Chow SP. Dynamic hip screw blade fixation for intertrochanteric hip fractures. J Orthop Surg. 2012; 20(3):302-6.

15. Arirachakaran A, Amphansap T, Thanindratarn P, Piyapittayanun P, Srisawat P, Kongtharvonskul J. Comparative outcome of PFNA, Gamma nails, PCCP, Medoff plate, LISS and dynamic hip screws for fixation in elderly trochanteric fractures: a systematic review and network meta-analysis of randomized controlled trials. Eur J Orthop Surg Traumatol. 2017;37:937-52.

16. Luo Q, Yuen G, Lau TW, Yeung K, Leung F. A biomechanical study comparing helical blade with screw design for sliding hip fixations of unstable intertrochanteric fractures. Sci World J. 2013;2013:351936.

17. Schwarzkopf R, Takemoto RC, Kummer FJ, Egol KA. Helical blade vs telescoping lag screw for intertrochanteric fracture fixation. Am J Orthop. 2011;40(9):452-6.

18. Stern R, Lubbeke A, Suva D, Miozzari H, Hoffmeyer P. Prospective randomised study comparing screw versus helical blade in the treatment of low-energy trochanteric fractures. Int Orthop. 2011;35(12):1855-61.

19. Kancherla R, Sankineni S, Trikha V, Kumar R, Malhotra R. Comment on Stern et al:: Prospective randomised study comparing screw versus helical blade in the treatment of low-energy trochanteric fractures. Int Orthop. 2012;36(5): 1109-10 (author reply 1111).

20. Stern LC, Gorczyca JT, Kates S, Ketz J, Soles G, Humphrey CA. Radiographic review of helical blade versus lag screw fixation for cephalomedullary 
nailing of low-energy peritrochanteric femur fractures: there is a difference in cutout. J Orthop Trauma. 2017;31(6):305-10.

21. Ma JX, Kuang MJ, Fan ZR, Xing F, Zhao YL, Zhang LK, Chen HT, Han C, Ma XL. Comparison of clinical outcomes with InterTan vs Gamma nail or PFNA in the treatment of intertrochanteric fractures: a meta-analysis. Sci Rep. 2017;7(1):15962

22. Yaozeng X, Dechun G, Huilin Y, Guangming Z, Xianbin W. Comparative study of trochanteric fracture treated with the proximal femoral nail antirotation and the third generation of gamma nail. Injury. 2010;41(12):1234-8.

23. Hong JB, Dan Y, Ouyang L, Liu Y, Xiong LM, Li S, Feng XB, Shao ZW, Yan C, Yang SH, et al. Biomechanical study on different lengths of PFNA fixation for unstable intertrochanteric femoral fractures. J Musculoskelet Neuronal Interact. 2017;17(4):299-302.

24. Shin WC, Seo JD, Lee SM, Moon NH, Lee JS, Suh KT. Radiographic outcomes of osteosynthesis using proximal femoral nail antirotation (PFNA) system in intertrochanteric femoral fracture: has PFNA II solved all the problems? Hip Pelvis. 2017;29(2):104-12.

25. Kler J, Godula R, Gazdzik T. Remarks on Gamma nail use in the treatment of trochanteric fracture of the femur. Chir Narzadow Ruchu Ortop Pol. 1998; 63(4):329-32.

\section{Publisher's Note}

Springer Nature remains neutral with regard to jurisdictional claims in published maps and institutional affiliations.

Ready to submit your research? Choose BMC and benefit from:

- fast, convenient online submission

- thorough peer review by experienced researchers in your field

- rapid publication on acceptance

- support for research data, including large and complex data types

- gold Open Access which fosters wider collaboration and increased citations

- maximum visibility for your research: over $100 \mathrm{M}$ website views per year

At $\mathrm{BMC}$, research is always in progress.

Learn more biomedcentral.com/submissions 